Open Access

\title{
Can we detect contract cheating using existing assessment data? Applying crime prevention theory to an academic integrity issue
}

\author{
Joseph Clare ${ }^{*}$, Sonia Walker and Julia Hobson
}

\author{
* Correspondence: \\ j.clare@murdoch.edu.au \\ Murdoch University, Murdoch, WA \\ Australia
}

\begin{abstract}
Objectives: Building on what is known about the non-random nature of crime problems and the explanatory capacity of opportunity theories of crime, this study explores the utility of using existing university administrative data to detect unusual patterns of performance consistent with a student having engaged in contract cheating (paying a third-party to produce unsupervised work on their behalf).

Methods: Results from an Australian university were analysed ( $N=3798$ results, $N=1459$ students). Performances on unsupervised and supervised assessment items were converted to percentages and percentage point differences analysed at the academic discipline-, unit-, and student-level, looking for non-random patterns of unusually large differences.

Results: Non-random, unusual patterns, consistent with contract cheating, were found at the academic discipline-, unit-, and student-level, with approximately $2.1 \%$ of students producing multiple unusual patterns.

Conclusions: These findings suggest it may be possible to use existing administrative data to identify assessment items that provide suitable opportunities for contract cheating. This approach could be used in conjunction with targeted problem-prevention strategies (based on situational crime prevention) to reduce the vulnerability of academic assessment items to contract cheating. This approach is worthy of additional research as it has the potential to help academic institutions around the world manage contract cheating; a problem that currently threatens the validity and integrity of tertiary qualifications.
\end{abstract}

Keywords: Academic integrity, Contract cheating, Rational choice, Routine activity theory, Situational crime prevention

\section{Introduction}

Contract cheating is a form of academic misconduct that, in some forms, involves students paying a third-party to produce an unsupervised assessment item that they subsequently submit as if it was their own work (Clarke \& Lancaster, 2006; Sivasubramaniam, Kostelidou, \& Ramachandran, 2016; Walker \& Townley, 2012). As is discussed below, there is good reason to believe that contract cheating displays patterns that are similar to those that criminology has typically observed for crime: non-randomness across offenders

(c) The Author(s). 2017 Open Access This article is distributed under the terms of the Creative Commons Attribution 4.0 International License (http://creativecommons.org/licenses/by/4.0/), which permits unrestricted use, distribution, and reproduction in any medium, provided you give appropriate credit to the original author(s) and the source, provide a link to the Creative Commons license, and indicate if changes were made. 
and targets caused by repeat offending and repeat victimization. For over three decades, routine activity theory (Cohen \& Felson, 1979) and the rational choice perspective (Cornish \& Clarke, 1986) have combined well to provide an opportunitybased explanation for the non-random patterns of crime and deviance in other contexts. This paper makes a novel contribution to the academic integrity area by exploring the capacity of these criminological theories to account for contract cheating. This is carried out by exploring the utility of a methodology for identifying repeat targets and repeat offenders, which assumes students who have engaged in contract cheating will perform 'unusually' better on unsupervised assessment items (such as take-home essays) relative to supervised assessment items (such as invigilated exams). By testing a series of difference rules designed to identify 'unusual' patterns of difference, this analysis looks to identify repeat offenders (students with multiple unusual patterns across units they have taken) and repeat victimisation (with certain units producing disproportionately large numbers of unusual patterns of difference). This methodology produces results that are consistent with expectations built on an opportunity-based account of crime. Given that the opportunity theories of crime underpin a huge number of successful targeted crime prevention interventions (see Felson \& Clarke, 1998, for a discussion), this exploratory methodology may have important implications for the prevention and management of the problem of contract cheating within higher education institutions.

\section{Prevalence and significance of contract cheating}

The practice of paying someone else to complete unsupervised academic assessments is not a new one, as demonstrated, for example, by the headline from the New York Times on July 10, 1971, suggesting that the, "Market in term papers is booming." Instead, it is more likely there have been markets for this type of transaction for as long as there have been unsupervised assignments in educational institutions. As with all other aspects of modern day life, recent times have seen a move towards online activity for purchasing assignments. Despite this, the increased ease of access to potential sources of purchased assignments may not have necessarily corresponded to an increase in the prevalence of contract cheating, with estimates from a 10-year study in Australia indicating that prevalence rates of contract cheating declined slightly from 3.5\% in 2004 to $2.8 \%$ in 2014 (Curtis \& Vardanega, 2016). Alternative estimates have placed contract cheating prevalence rates close to 1\% (Maxwell, Curtis, \& Vardanega, 2006) and as high as $7.9 \%$ (Zafarghandi, Khoshroo, \& Barkat, 2012). As with all other survey estimates for crime and deviant behaviour, variations in survey methodologies will have influenced these results (see Skogan, 1981, for a seminal discussion of these issues). Despite these relatively small prevalence estimates, the issue of contract cheating still poses a significant problem for tertiary institutions. In addition to potentially devaluing qualifications and disadvantaging conscientious students, this practice creates the possibility of unskilled, unqualified contract cheaters using unethically-gained qualifications to secure employment that they are not capable of undertaking. Further to this, because the product purchased during a contract cheating transaction is intended to be 'original', typical methods of plagiarism detection (such as web-based text pattern matching software) are unlikely to be consistently effective as an apprehension tools to address this problem. 
Wallace and Newton recently indicated that, "the single greatest need is for more high-profile research in [the contract cheating] area, to educate educators about the existence and detail of the problem" (Wallace \& Newton, 2014, p. 236). With this in mind, it is worth exploring whether the patterns that have been consistently demonstrated across a range of other crime problems hold true for contract cheating. These patterns include repeat offending, repeat victimisation, and the role that motivation plays in decisions to exploit an opportunity to offend. If this is the case, it will be a logical extension to connect this academic misconduct issue to a theoretical platform that has been demonstrated to help reduce crime problems: the opportunity theories of crime. The next section outlines the existing evidence to demonstrate this link.

\section{Opportunity and offending: Does what we know about crime problems relate to contract cheating?}

Repeat offending is a consistently demonstrated pattern within criminological research, whereby a small number of offenders are responsible for a very large amount of crime. Budd, Sharp, and Mayhew (2005) identified this pattern through a UK-based survey, which identified that $2 \%$ of the self-reported offender sample were responsible for $82 \%$ of all reported offences. Chronic repeat offending has also been observed within contract cheating research. For example, in an analysis of students looking to purchase computer code from third-parties, Clarke and Lancaster (2006) found that only 8.1\% of the 236 identified contract cheaters engaged in this activity on a single occasion, compared to the $2.5 \%$ of the offenders who had engaged in this activity between 51 and 200 times in a two-month period. Curtis and Clare (2017) found that $62.5 \%$ of students who reported engaging in contract cheating across a number of self-report academic misconduct surveys indicated that they had done so on multiple occasions. Furthermore, in another self-report survey asking about engaging in contract cheating, Bailey, Tomar, and Chu (2012) reported that $3.7 \%$ of the students surveyed admitted partaking once or twice, while $3.2 \%$ admitted contracting cheating three or more times. Based on existing evidence, therefore, there is good reason to believe contract cheating involves a group of students who are repeat offenders.

It is also clear from criminological research that crime problems are non-randomly distributed, clustering across time and space (e.g., Curman, Andresen, \& Bratingham, 2015). Crime is also non-randomly distributed with respect to victimisation (e.g., Farrell, Phillips, \& Pease, 1995) and targets (e.g., Townsley, Homel, \& Chaseling, 2003) with a very small number of targets accounting for a large proportion of victimisation. For example, Pease and Ignatans (2016) recently demonstrated that $1 \%$ of UK households experienced just under one-quarter of vehicle crimes, almost half of property crimes, and more than one-third of personal crimes. As with the non-random patterns of contract cheating offending, Lancaster and Clarke (2012) examined 627 postings on a commercial site offering 'writing solutions' for students and identified nonrandomness with respect to subject area (24.5\% of all postings related to 'Business and Admin studies' assignments), level of study ( $71.0 \%$ of postings related to undergraduate assessments), and country of origin (where $42.3 \%$ of postings that could be attribute to a country had originated from the UK). Thus, there is also evidence of a non-random distribution of contract cheating across academic disciplines, suggesting that some unsupervised assessment 'targets' are more suitable for this activity than others. 
Given these parallels in empirical findings, and in the absence of academic integrity theory that can explain these non-random patterns, it is important to outline two criminological theories that combine well to explain similar patterns in a different context. First, routine activity theory (originally discussed in the seminal work by Cohen \& Felson, 1979), predicts that for a predatory crime to occur a motivated offender must co-occur in time and space with a suitable target and the absence of a capable guardian. This opportunity structure is not always present, which explains why offenders do not constantly offend. Second, the rational choice perspective (first discussed in the seminal work by Cornish \& Clarke, 1986) explains that offenders make crime-specific 'rational' choices, 'bounded' by factors such as time, cognitive ability, and available information, and influenced by the perceived costs and benefits of their actions. The rational choice perspective makes the crucial assumption that crime decisions can be made by anyone, provided they perceive the reward to outweigh the risk and effort. Together, these theories contribute to an opportunity-based explanation for crime (see Felson \& Clarke, 1998, for a full discussion) that can account for variations in offending behaviour across contexts, with offenders acting selectively about where, when, and against whom to offend.

To complete the connection to the opportunity account of offending it is important to note that contract cheating research also demonstrates the likelihood that offender motivation is influenced by the perceived risk, rewards, and effort involved with this decision. In a study by Rigby, Burton, Balcombe, Bateman, and Mulatu (2015), over $50 \%$ of students presented with a hypothetical decision-making task indicated they were willing to cheat on university assessment items if the risk of detection was low. Furthermore, this likelihood increased for students for whom English was a foreign language. In combination, both of these findings indicate the role of rational decision-making in the choice to partake in contract cheating. The importance of rational choice and opportunity has also been demonstrated for academic misconduct more broadly by Ogilvie and Stewart (2010), who utilized a scenario-based survey of 536 undergraduate students to demonstrate that the intention to engage in plagiarism was significantly predicted by (a) the situational perceptions of risk and reward and (b) the individual decision-maker's academic self-efficacy. Opportunity theory can explain the inconsistent nature of deviant behaviour over time in a way that appeals to factors such as understanding/accepting academic integrity policy, existence of honour codes, and perceptions of peer behaviour cannot (McCabe \& Trevino, 1993).

\section{Aims and expectations of research}

To summarize some main points, it seems reasonable to assume that (a) the prevalence of contract cheating is relatively low (around 3\%), (b) repeat offending is likely, (c) some assessment items provide more suitable targets for contract cheating than others, (d) opportunity theories of crime problems predict contract cheating will occur in those situations when a motivated offender coincides with a suitable unsupervised assessment item, and (e) students who engage in contract cheating will perform 'unusually' better on unsupervised assessment items (such as take-home essays) relative to supervised assessment items (such as invigilated exams). In combination, these findings provide the platform for the purpose of this paper: to explore whether a methodology can be developed for identifying repeat targets and repeat offenders. The methodology that is tested, 
below, uses a series of difference rules that examine individual student's performances within-units for unsupervised and supervised assessment items.

In combination, the prior research findings and the opportunity theory platform allow some clear hypotheses for this exploratory analysis. First, looking at the suitable targets (unsupervised assessment items), it is expected that at the subject area-level and the unit-level there will be a general non-randomness of these unusual patterns, produced because some assignments are more suitable for contract cheating than others (paralleling previous findings relating to repeat victimisation in criminological literature). Second, looking for motivated offenders, it is anticipated a small percentage of individual students will produce multiple unusual patterns of performance on supervised and unsupervised assessment items across units they have taken (paralleling previous findings relating to repeat offending in criminal contexts).

\section{Data and methodology}

Sample

Administrative records from one year of units (sometimes called 'courses', 'classes', 'subjects', or 'modules' at Universities) from an Australian Law School were analysed. This sample contained 3798 unit results from 1459 students (average 2.6 units per student and a range from 1 unit to 9 units completed by each student). The units were offered in a few major discipline areas: criminology, law, legal studies, and University preparatory units. These units were from within the administrative unit of the authors and so this set of results constituted an opportunity sample to trial this method. This research was approved by the University's Human Research Ethics sub-committee.

\section{Data preparation}

To align with University assessment policy, units in this sample had between two to three assessment items. Across-units, the largest components of the marks came from the combination of an unsupervised assessment item (a report or essay, generally worth between $40 \%$ and $50 \%$ of the unit total) and a supervised assessment item (an invigilated exam, also generally worth between $40 \%$ and 50\%). To account for the different weighting of supervised and unsupervised assessment items across units, students' performances were converted to percentages. Five difference rules were generated to identify large, unusual patterns of difference in performance between unsupervised and supervised assessment items. Given the exploratory nature of this novel approach to identifying unusual differences there was no research-based precedent for the researchers to draw on when developing these rules. As a result, across the five rules, the researchers utilised a mixture of expert opinion from academics and statistical significance.

When contextualising the first four difference rules, it is important to explain that within this University certain grade cut-offs influence the grade band that the student's performance fell into. Scores of $80 \%$ or more were classed as 'High Distinctions', scores between $70 \%$ and $79 \%$ were classed as 'Distinctions', scores between $60 \%$ and $69 \%$ were classed as 'Credits', scores between 50\% and 59\% were classed as 'Passes', and scores of less than 50 were graded as 'Fails'. Building on these grade categories and in consultation with colleagues, the first four difference rules were designed to identify unusual 
combinations of performance within a unit where unsupervised and supervised assessment performance fell into distinctly different grade bands, as follows:

Unusual Pattern 1 (UP1): Unsupervised mark $\geq 70 \%$ and Supervised mark $\leq 50 \%$.

Unusual Pattern 2 (UP2): (Unsupervised mark - Supervised mark) $\geq 25$ percentage points.

Unusual Pattern 3 (UP3): Unsupervised mark $\geq 80 \%$ and (Unsupervised mark Supervised mark) $\geq 40$ percentage points.

Unusual Pattern 4 (UP4): Unsupervised mark $\geq 60 \%$ and Supervised mark $\leq 30 \%$.

In order to account for the potential normality of some reduction in performance between unsupervised assessment items (that students could work on over time and submit when ready) compared to invigilated exams, the fifth difference rule used drew on the properties of the difference distribution overall. Across all unit records the mean and standard deviation of difference between unsupervised and supervised assessment items was calculated. These values were then used to calculate a one-directional $95 \%$ confidence interval cut-off and individual student difference scores within-units were compared to this score and significant differences were flagged, as follows:

Unusual Pattern 5 (UP5): Individual [Unsupervised mark - Supervised mark] difference > one-directional 95\% confidence interval Population [Unsupervised mark Supervised mark] difference.

The administrative records were manipulated in a way that meant student performance across all of the units could be examined. Unit codes are anonymized when presented, below (using unique, but deidentified label names).

\section{Results}

Table 1 displays that a 'normal' percentage point difference between Unsupervised and Supervised scores was 4.4 $(S D=14.9)$. These values generated UP5, above. The overall frequency for unusual patterns is shown in the bottom of Table 1, indicating that UP2 is the most frequently occurring (8.1\% of student results), followed by UP5 (5.0\% of results), UP1 (4.6\% of results), and then UP3 and UP4 both occurred less than $1 \%$ of the time. (For interest, the frequency of the inverse of each of these unusual patterns are included in the bottom line of Table 1). Looking within-academic areas it is clear that there is initial support for the expectation that there will be a general non-randomness of unusual difference patterns with some subjects producing more unusual patterns than

Table 1 Number of students, differences between unsupervised and supervised assessment items (percentage point), and unusual patterns (UP \% of students) by academic area

\begin{tabular}{|c|c|c|c|c|c|c|c|c|}
\hline \multirow[b]{2}{*}{ Academic area } & \multirow[b]{2}{*}{ N } & \multicolumn{2}{|c|}{ Unsupervised\% - supervised\% } & \multirow[b]{2}{*}{ UP1\% } & \multirow[b]{2}{*}{ UP2\% } & \multirow[b]{2}{*}{ UP3\% } & \multirow[b]{2}{*}{ UP4\% } & \multirow[b]{2}{*}{ UP5\% } \\
\hline & & Avg. & SD & & & & & \\
\hline Justice studies (BJU) & 354 & 1.9 & 14.1 & $1.7 \%$ & $4.2 \%$ & $0.0 \%$ & $0.0 \%$ & $1.4 \%$ \\
\hline Criminology (CRM) & 641 & 6.4 & 17.7 & $8.4 \% * *$ & $14.5 \% * *$ & $1.7 \% \%^{* *}$ & $1.9 \% * *$ & $9.7 \% * *$ \\
\hline Bachelor Law (LAW) & 1282 & 5.8 & 14.2 & $5.5 * \%$ & $8.5 \%$ & $0.9 \%$ & $0.7 \%$ & $4.7 \%$ \\
\hline Legal studies (LEG) & 240 & 1.1 & 14.9 & $3.8 \%$ & $5.4 \%$ & $0.4 \%$ & $0.8 \%$ & $4.6 \%$ \\
\hline Bachelor Law (LLB) & 1161 & 3.6 & 14.0 & $3.0 \%$ & $6.6 \%$ & $0.3 \%$ & $0.3 \%$ & $4.2 \%$ \\
\hline Master Law (LLM) & 120 & 0.1 & 13.2 & $1.7 \%$ & $2.5 \%$ & $0.0 \%$ & $0.0 \%$ & $1.7 \%$ \\
\hline \multirow[t]{2}{*}{ Total } & 3798 & 4.4 & 14.9 & $4.6 \%$ & $8.1 \%$ & $0.7 \%$ & $0.7 \%$ & $5.0 \%$ \\
\hline & & & Inverse rule violation & $1.2 \%$ & $2.6 \%$ & $0.1 \%$ & $0.4 \%$ & $4.9 \%$ \\
\hline
\end{tabular}

$Z$-proportion indicated significantly larger more frequent relative to the whole sample ${ }^{*} p<.05,{ }^{* *} p<.01(Z>1.64$, one-tailed) 
others. The $Z$-proportion calculations (undertaken manually) indicate that at the academic area level criminology (CRM) units have a significantly greater frequency of all five unusual pattern rules and law units had a significantly greater frequency of UP1.

Drilling down further within academic areas there is also a non-random distribution of unusual performance at the unit-level (Table 2, which uses the same academic area codes explained in Table 1 and appends a unique, deidentified capital letter for each unit). Looking first at criminology units (demonstrated in Table 1 to be generally very unusual as an academic area relative to the norm), three of the units (CRM_A, CRM_D, and CRM_G) did not display any unusual patterns and had difference scores (Unsupervised marks - Supervised marks) that closely aligned with the full dataset. In contrast, the other five criminology units (CRM_B, CRM_C, CRM_E, CRM_F, and CRM_H) all displayed significantly more frequent unusual patterns relative to the rest of unit results in the sample (with differences flagged in the Table). Next, looking at law units (which appeared to have average difference patterns at the academic area, Table 1), LAW_E (UP1, UP2, UP3, and UP5) and LAW_J (UP1 and UP2) that displayed significantly more frequent unusual patterns than expected. Finally, looking within the Bachelor of Laws (LLB) academic area, which had a very low incidence of unusual patterns at the academic area level (Table 1), there was still one unit (LLB_J) that produced a much greater frequency of unusual patterns for UP1 and UP2. There were seven units (CRM_B, CRM_C, CRM, F, CRM_H, LAW_E, LAW_J, and LLB_J) that violated at least two of the risk rules at a rate that was significantly greater than expected. In combination, with respect to the possibility of repeat victimization of unsupervised assessment items, the findings displayed in Table 1 and Table 2 provide good support for the expectation of a general non-randomness of unusual difference score patterns at the subject area level and the unit level.

Next, the difference scores and unusual patterns were analysed at the individual student level. As explained above, it was anticipated a small percentage of individual students would produce multiple unusual difference score patterns across units they took. To test this expectation, the frequency of rule unusual patterns and probability of multiple occurrences per student are displayed in Fig. 1. Looking first at UP1 [Fig. 1 (a)], it is clear that the majority of students never produced this difference $(89.0 \%), 9.9 \%$ did so once, and 15 students did so on two or more occasions. The expected rule violation lambda $(\lambda)=0.12$ with a probability of 2 or more violations $p<.01$. Similar patterns are displayed for UP2 (Fig. 1 (b), $\lambda=0.21, p(\geq 2$ violations) $<.02$ ), UP3 (Fig. 1 (c), $\lambda=0.02$, $p(\geq 1$ violation) $<.02)$, UP4 (Fig. 1 (d), $\lambda=0.02, p(\geq 1$ violations) $<.02)$, and UP5 (Fig. 1 (e), $\lambda=0.13, p(\geq 2$ violations) <.01). It is also clear from Fig. 2 that, as expected, repeat unusual patterns within an individual were found. The 31 students $(2.1 \%$ of the student population analysed here) whose performances are summarized in Fig. 2 produced UP2 at least twice, and this figure shows their overall rate of unusual performance as a proportion of all units undertaken (captured in the far right column as a percentage of unusual units completed). It is clear from this figure that repeated unusual patterns across units were common for this sample. Students 3, 8, 9, 14, 16, 22, 25, and 31 had unusual patterns of results for all of the units they completed ( 2 units per student) and Students 2, 17, 23, and 27 had unusual patterns of results for 3 out of 4 of the units they completed. 
Table 2 Number of students, differences between unsupervised and supervised assessment items (percentage point), and unusual patterns (UP \% of students) by unit within academic area

\begin{tabular}{|c|c|c|c|c|c|c|c|c|}
\hline \multirow[b]{2}{*}{ Unit } & \multirow[b]{2}{*}{$N$} & \multicolumn{2}{|c|}{ Unsupervised\% - supervised\% } & \multirow[b]{2}{*}{ UP1\% } & \multirow[b]{2}{*}{ UP2\% } & \multirow[b]{2}{*}{ UP3\% } & \multirow[b]{2}{*}{ UP4\% } & \multirow[b]{2}{*}{ UP5\% } \\
\hline & & Avg. & SD & & & & & \\
\hline BJU_A & 182 & 2.2 & 15.3 & $2.2 \%$ & $5.5 \%$ & $0.0 \%$ & $0.0 \%$ & $1.7 \%$ \\
\hline BJU_B & 119 & 2.1 & 14.7 & $1.7 \%$ & $4.2 \%$ & $0.0 \%$ & $0.0 \%$ & $1.7 \%$ \\
\hline BJU_C & 53 & 0.3 & 5.8 & $0.0 \%$ & $0.0 \%$ & $0.0 \%$ & $0.0 \%$ & $0.0 \%$ \\
\hline CRM_A & 146 & 2.5 & 13.9 & $4.1 \%$ & $6.2 \%$ & $0.0 \%$ & $0.0 \%$ & $2.1 \%$ \\
\hline CRM_B & 77 & 8.0 & 20.6 & $13.0 \%{ }^{*}$ & $19.5 \% * *$ & $5.2 \% *$ & $0.0 \%$ & $15.6 \% \%^{* *}$ \\
\hline CRM_C & 111 & 6.9 & 20.0 & $10.8 \%{ }^{*}$ & $22.5 \% * *$ & $0.0 \%$ & $3.6 \%{ }^{*}$ & $13.5 \%^{* *}$ \\
\hline CRM_D & 88 & 4.4 & 14.5 & $4.6 \%$ & $5.7 \%$ & $1.1 \%$ & $0.0 \%$ & $2.3 \%$ \\
\hline CRM_E & 45 & 6.7 & 19.3 & $8.9 \%$ & $17.8 \% *$ & $4.4 \%$ & $0.0 \%$ & $11.1 \%$ \\
\hline CRM_F & 41 & 21.7 & 16.3 & $12.2 \%$ & $41.5 \%^{* *}$ & $0.0 \%$ & $17.1 \%^{* *}$ & $36.6 \%$ ** \\
\hline CRM_G & 65 & -0.5 & 15.4 & $1.5 \%$ & $1.5 \%$ & $0.0 \%$ & $0.0 \%$ & $0.0 \%$ \\
\hline CRM_H & 68 & 12.1 & 16.7 & $17.7 \%^{* *}$ & $19.1 \%^{* *}$ & $5.9 \%^{*}$ & $1.5 \%$ & $14.7 \%^{* *}$ \\
\hline LAW_A & 100 & 6.0 & 15.1 & $8.0 \%$ & $10.0 \%$ & $1.0 \%$ & $3.0 \%$ & $8.0 \%$ \\
\hline LAW_B & 66 & 3.7 & 11.6 & $3.0 \%$ & $3.0 \%$ & $1.5 \%$ & $0.0 \%$ & $1.5 \%$ \\
\hline LAW_C & 24 & 6.9 & 19.7 & $16.7 \%$ & $12.5 \%$ & $0.0 \%$ & $0.0 \%$ & $8.3 \%$ \\
\hline LAW_D & 143 & 7.9 & 13.5 & $4.9 \%$ & $8.4 \%$ & $1.4 \%$ & $0.7 \%$ & $3.5 \%$ \\
\hline LAW_E & 51 & 19.8 & 16.3 & $27.5 \%^{* *}$ & $43.1 \%^{* *}$ & $7.8 \%{ }^{*}$ & $5.9 \%$ & $23.5 \%$ ** \\
\hline LAW_F & 50 & 5.9 & 17.9 & $8.0 \%$ & $14.0 \%$ & $0.0 \%$ & $0.0 \%$ & $10.0 \%$ \\
\hline LAW_G & 60 & -6.7 & 17.9 & $0.0 \%$ & $6.7 \%$ & $0.0 \%$ & $0.0 \%$ & $3.3 \%$ \\
\hline LAW_H & 59 & 7.5 & 12.9 & $5.1 \%$ & $6.8 \%$ & $1.7 \%$ & $0.0 \%$ & $6.8 \%$ \\
\hline LAW_I & 76 & -0.6 & 14.7 & $4.0 \%$ & $2.6 \%$ & $1.3 \%$ & $0.0 \%$ & $1.3 \%$ \\
\hline LAW_J & 69 & 9.5 & 17.2 & $13.0 \%^{*}$ & $20.3 \% * *$ & $0.0 \%$ & $2.9 \%$ & $10.1 \%$ \\
\hline LAW_K & 70 & 2.0 & 12.5 & $1.4 \%$ & $2.9 \%$ & $0.0 \%$ & $0.0 \%$ & $1.4 \%$ \\
\hline LAW_L & 70 & 5.9 & 13.1 & $5.7 \%$ & $10.0 \%$ & $0.0 \%$ & $0.0 \%$ & $2.9 \%$ \\
\hline LAW_M & 125 & 8.8 & 10.1 & $6.4 \%$ & $5.6 \%$ & $0.0 \%$ & $0.0 \%$ & $2.4 \%$ \\
\hline LAW_N & 59 & 9.4 & 5.5 & $0.0 \%$ & $0.0 \%$ & $0.0 \%$ & $0.0 \%$ & $0.0 \%$ \\
\hline LAW_O & 81 & 4.5 & 12.4 & $2.5 \%$ & $7.4 \%$ & $0.0 \%$ & $0.0 \%$ & $2.5 \%$ \\
\hline LAW_P & 179 & 4.6 & 11.2 & $0.6 \%$ & $3.9 \%$ & $0.6 \%$ & $0.0 \%$ & $2.8 \%$ \\
\hline LEG_A & 126 & 4.7 & 15.4 & $4.8 \%$ & $9.5 \%$ & $0.8 \%$ & $1.6 \%$ & $8.7 \%$ \\
\hline LEG_B & 106 & -3.4 & 13.1 & $0.9 \%$ & $0.0 \%$ & $0.0 \%$ & $0.0 \%$ & $0.0 \%$ \\
\hline LLB_A & 166 & -1.3 & 16.7 & $1.8 \%$ & $6.6 \%$ & $0.0 \%$ & $0.6 \%$ & $4.8 \%$ \\
\hline LLB_B & 161 & 1.3 & 9.8 & $0.6 \%$ & $2.5 \%$ & $0.0 \%$ & $0.0 \%$ & $1.9 \%$ \\
\hline LLB_C & 172 & 5.4 & 13.6 & $1.2 \%$ & $6.4 \%$ & $0.0 \%$ & $0.0 \%$ & $4.1 \%$ \\
\hline LLB_D & 163 & 4.3 & 11.0 & $1.8 \%$ & $2.5 \%$ & $0.0 \%$ & $0.0 \%$ & $1.8 \%$ \\
\hline LLB_E & 180 & 10.3 & 12.1 & $5.0 \%$ & $11.1 \%$ & $0.0 \%$ & $1.1 \%$ & $6.1 \%$ \\
\hline LLB_F & 40 & -4.7 & 14.3 & $0.0 \%$ & $0.0 \%$ & $0.0 \%$ & $0.0 \%$ & $0.0 \%$ \\
\hline LLB_G & 26 & -15.5 & 7.7 & $0.0 \%$ & $0.0 \%$ & $0.0 \%$ & $0.0 \%$ & $0.0 \%$ \\
\hline LLB_H & 27 & -8.9 & 9.7 & $0.0 \%$ & $0.0 \%$ & $0.0 \%$ & $0.0 \%$ & $0.0 \%$ \\
\hline LLB_I & 168 & 7.3 & 13.4 & $6.6 \%$ & $10.7 \%$ & $0.6 \%$ & $0.0 \%$ & $7.1 \%$ \\
\hline LLB_J & 36 & 11.6 & 14.6 & $16.7 \%^{*}$ & $22.2 \%{ }^{*}$ & $2.8 \%$ & $0.0 \%$ & $13.9 \%$ \\
\hline LLB_K & 22 & -7.5 & 12.7 & $0.0 \%$ & $0.0 \%$ & $0.0 \%$ & $0.0 \%$ & $0.0 \%$ \\
\hline LLM_A & 37 & 1.1 & 14.2 & $2.7 \%$ & $5.4 \%$ & $0.0 \%$ & $0.0 \%$ & $5.4 \%$ \\
\hline LLM_B & 51 & 1.8 & 12.6 & $2.0 \%$ & $2.0 \%$ & $0.0 \%$ & $0.0 \%$ & $0.0 \%$ \\
\hline LLM_C & 32 & -3.8 & 12.5 & $0.0 \%$ & $0.0 \%$ & $0.0 \%$ & $0.0 \%$ & $0.0 \%$ \\
\hline
\end{tabular}




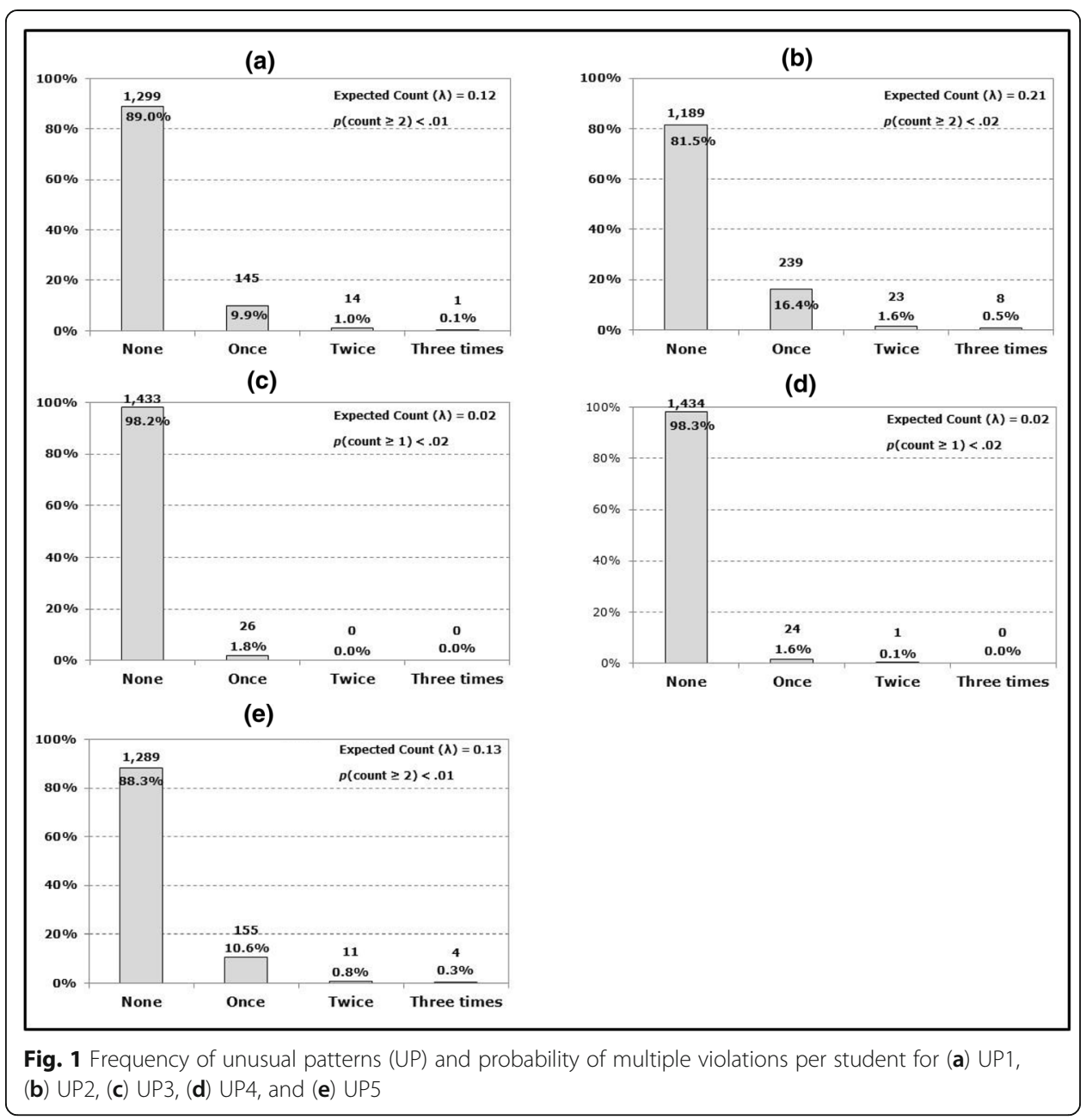

\section{Discussion}

\section{Implications of these findings}

Bearing in mind the potential for Type 1 and Type 2 errors in this case (explored more fully, below, in the Limitations and Future Directions section), the results of this exploratory analysis provide clear support for the hypotheses based on prior research findings relating to contract cheating and an opportunity theory perspective on crime. Significant area-level and unit-level variation of unusual patterns was observed, which is consistent with the expectation that some assignments are more suitable targets for contract cheating. Significant variation was also observed within the student performances analysed here, with a small percentage of students observed to produce multiple unusual patterns of performance on supervised and unsupervised assessment items across units they took (paralleling previous findings relating to repeat offending for contract cheating, e.g., Curtis \& Clare, 2017).

As there is potentially a legitimate need for some of these third-party resources (e.g., code writing contractors) and because the provision of these third-party services is not illegal, prevention targeted at providers of these services does not appear feasible. Research has demonstrated it is relatively inexpensive to purchase contract cheating 


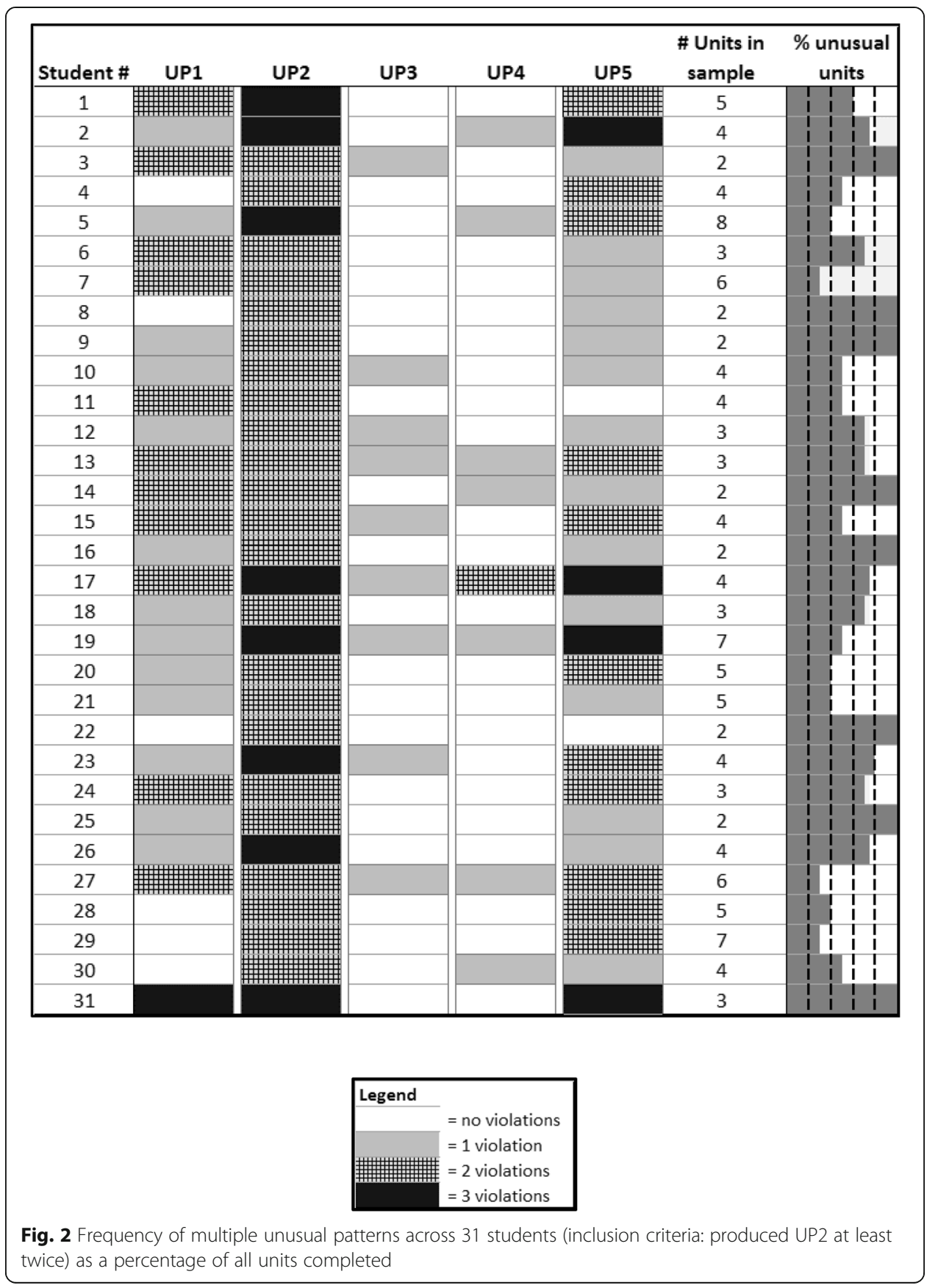

pieces (Clarke \& Lancaster, 2013; Sivasubramaniam, Kostelidou, \& Ramachandran, 2016), requests for assignments can be completed very quickly and for every contractor awarded a job, there are an average of 10 others offering to complete it (Wallace \& Newton, 2014). Recent research from Australia has also indicated that purchased assignments can also be of high quality, with a sample of purchased assignments being scored marks ranging from $71 \%$ to $89 \%$ when marked by unsuspecting academics (Lines, 2016). Given the consistency of contract cheating patterns with those observed for crime problems, it is worth considering the role that effective crime/problem ${ }^{1}$ prevention strategies could play in reducing the opportunity for contract cheating. 


\section{Opportunity reduction as a jumping-off point for targeted prevention of contract cheating}

Translating the offender-target-guardian trifecta from routine activity theory (Cohen \& Felson, 1979) to the issue of contract cheating, these roles are filled by the student (when motivated to engage in contract cheating) and the unsupervised assessment item (simultaneously both the time/place and target of the problem). Eck (2003) utilized routine activity theory to develop the crime (or problem) triangle. The inner layer of the crime triangle shows how each of the offender-target-guardian roles can be influenced by a controller who has the potential to reduce the opportunity for the problem, with place managers controlling places, guardians controlling targets, and handlers controlling offenders (with this third controller relationship first proposed by Felson, as discussed in Tillyer \& Eck, 2011). The outer layer of the crime triangle demonstrates that controllers can be influenced by super controllers who exert influence on handlers, managers, and guardians to prevent the underlying problem (Eck \& Eck, 2012; Sampson \& Eck, 2008; Sampson, Eck, \& Dunham, 2010). Super controllers influence controllers to make cost-benefit decisions that will reduce the likelihood of problems occurring. This can occur through 'formal,' 'diffuse', and 'personal' mechanisms. In brief, super controllers can rely on authority provided by (1) organizations, (2) contracts, (3) financial commitments, (4) regulations, (5) the courts, (6) political institutions, (7) the markets, (8) the media, (9) groups, and (10) families (see Sampson, Eck, \& Dunham, 2010, for a full discussion of this typology).

Figure 3 demonstrates these role relationships with respect to the problem of contract cheating. This diagram helps demonstrate the potential 'directions' for new pressures that could be applied to reduce the suitability of a specific opportunity for contract cheating. At the inner-layer of the triangle, the academic integrity policies and procedures operate in the formal handler role, exerting prevention-focused influence on potentially motivated offenders. Whilst these procedures are effective when academic misconduct is detected, this influence is dependent on catching students in the first instance. As explained above, because contract cheating transactions are intended to produce 'original' output, plagiarism detection pattern matching software is likely to be ineffective as an apprehension tool for this problem. It is also possible that informal handlers (such as family and friends of students considering engaging in contract cheating) are exerting influence over some motivated students at present, but the extent to which this could be the case is not known. Looking to the other sides of the crime triangle, the type of assessment item that is set, the content of the unit, and the decisions made by the unit coordinator in each case will have a direct influence on the opportunity present within a specific academic unit to engage in contract cheating.

In addition to helping understand why there is non-random variation across units and students with respect to contract cheating, the crime triangle depicted in Fig. 3 also provides a starting point for designing targeted interventions to minimize the likelihood of contract cheating taking place. It is clear from this model that dealing with the locally-focused opportunity structure of assessment items within problem units is much more likely to be effective at preventing this problem. Across problem contexts, in partnership with the rational choice perspective (Cornish \& Clarke, 1986), this framework helps handlers, guardians, and place managers make rational decisions about when to intervene to reduce the occurrence of problems as a consequence of the perceived risk, 


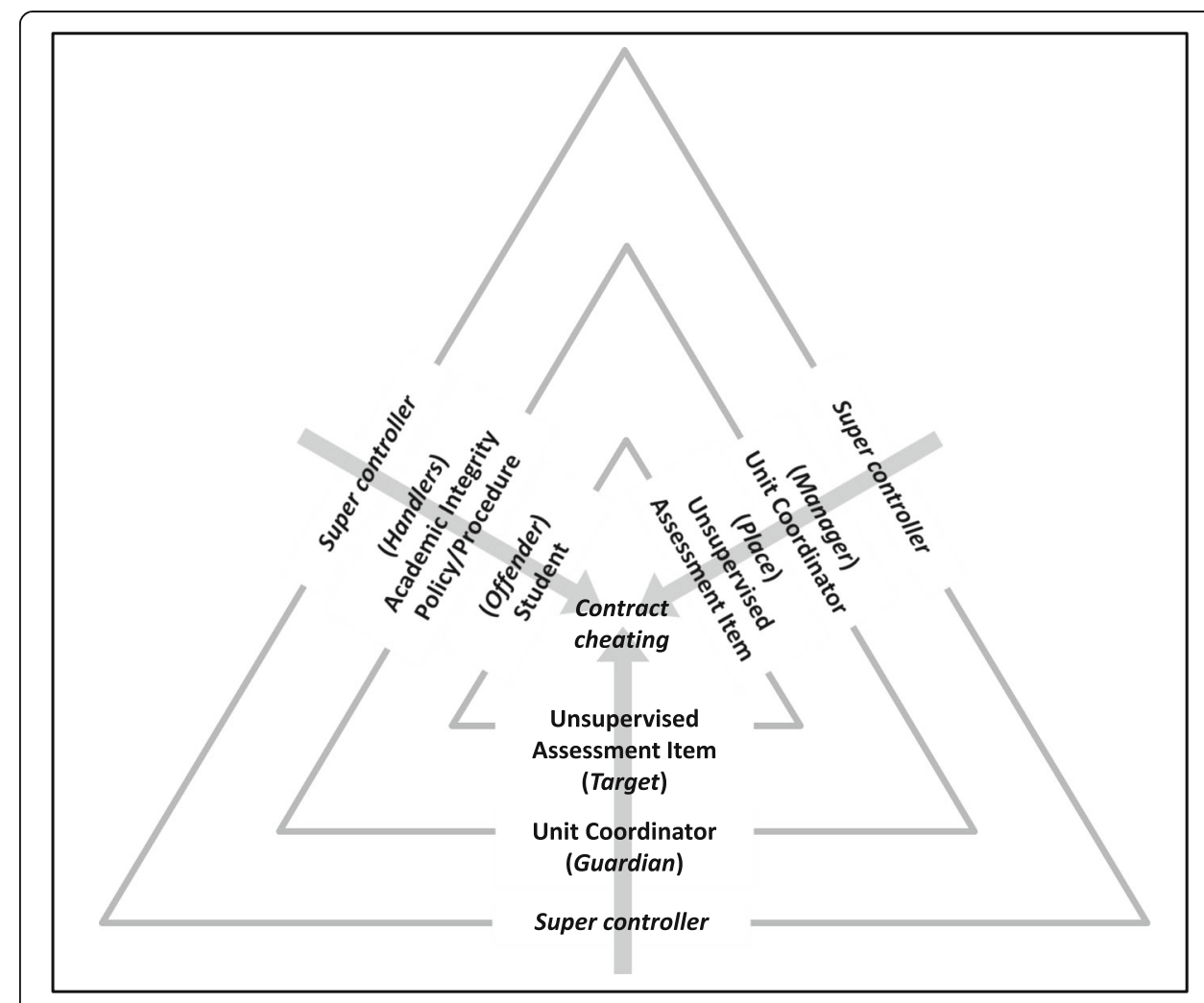

Fig. 3 The problem triangle for contract cheating problems, adapted from Sampson et al. (2010)

reward, effort, excuses, and provocations involved with action. These factors combine to provide structure for the twenty-five techniques of situational crime prevention (Cornish \& Clarke, 2008), which has been demonstrated to reduce and prevent a huge range of crime problems (see www.popcenter.org for examples). Recent work by Hodgkinson, Curtis, MacAlister, and Farrell (2015) has developed a portfolio of tactics for discouraging academic misconduct that they located within the 25 techniques of situational crime prevention. Using the methodology for identifying repeat unusual patterns at the student-, unit-, and discipline-level, it would be possible to use the work by Hodgkinson and colleagues to design targeted interventions that manipulate the risk, reward, and effort for students (motivated offenders), adjust the suitability of unsupervised assessment items (the problem target/place), and make changes at the unit-level (management and guardianship), targeting the influence of handlers (informal and formal) and super controllers (including the University, as well as the media and potentially policies relating to access to websites that promote contract cheating). This approach has been used very successfully to reduce the opportunity for contract cheating in a business capstone unit in Australia (Baird \& Clare, Removing the opportunity for contract cheating in business capstones: a crime prevention case study, submitted for review).

\section{Limitations and future directions}

As mentioned previously, it is important to discuss some caveats to these conclusions. First, in the absence of any convictions or confessions from students, it is entirely 
possible that this methodology has created a proxy for something other than contract cheating. In the first instance, Type 1 errors (false positives) may have been produced by students who are terrible at exams or supervised assessment items that were too difficult or inappropriate for the unit objectives. If this is the case, then potentially this approach provides a way for identifying students that need additional educational support and/or assessment content that needs to be reconsidered and improved. Alternatively, Type 2 errors might mean that this approach is too arbitrary, and 'misses' contract cheaters who do 'just-well-enough' on exams to escape the attention of these risk rules. Given students cannot control the outcome of either assessment item - they can only control the effort - it is unlikely this would prevent a repeat offender escaping the attention of these rules when their performance is considered across multiple units. So while it cannot be concluded that the patterns discussed above are capturing alland-only contract cheating, it is definitely the case that this methodology is exposing non-random problems, which suggests this information provides a jumping-off point for targeted problem-prevention in a manner that has been demonstrated to work in other problem contexts. Further to this, information was presented at a Western Australian contract cheating forum demonstrating individual case studies of contract cheaters for which large differences were observed between their performance on supervised and unsupervised assessment items (Jackson, 2016).

Future research should seek to replicate this approach using data from other universities. The source of this analysis was administrative data that is collected as a byproduct of normal assessment processes, so it is likely that other institutions will be wellplaced to look for patterns within their own existing information. This research team is already undertaking follow-up analysis of individual student characteristics for those identified as producing a disproportionate number of unusual performances as well as looking into the types of assessment items that do (and do not) produce unusual results at a high rate. In principle, it would be possible to develop targeted intervention strategies that could be trialled to try and reduce the frequency of unusual patterns of performance that are consistent with contract cheating behaviour. There is also potential to undertake backwards facing research that uses confirmed cases of contract cheating to assess past performances for guilty students in other units they have undertaken.

\section{Conclusions}

As has been demonstrated across contexts, successful, sustainable problemprevention needs to be built on strategies that are targeted, collaborative, multifaceted, logistically feasible (with respect to time, cost, and resources), and compatible with existing policy and legislation (Scott \& Goldstein, 2005). The same will be true for prevention strategies aimed at contract cheating. The overarching commitment needs to be to implement a strategy designed to reduce the opportunity to contract cheat. The way this can be achieved will be specific to each situation. Using data to identify unusual patterns of student performance at the individual- and unit-level provides one potential avenue for targeted intervention that is definitely worthy of further investigation. Manipulating the three sides of the problem triangle using the situational crime prevention techniques means that the success of this approach does not rely on increased apprehension. 


\section{Endnote}

${ }^{1}$ To draw this parallel is not to comment either way as to whether contract cheating is criminal.

\section{Authors' contribution}

JC conceived of the study, undertook all analysis, and drafted the manuscript. SW and JH participated in the design and coordination of the study and drafted the manuscript. All authors read and approved the final manuscript.

\section{Competing interests}

The authors declare that they have no competing interests.

\section{Publisher's Note}

Springer Nature remains neutral with regard to jurisdictional claims in published maps and institutional affiliations.

Received: 4 May 2017 Accepted: 2 August 2017

Published online: 08 August 2017

\section{References}

Bailey J, Tomar D, Chu J. "Paying for plagiarism." http://go.turnitin.com/webcast/paying-for-plagiarism. Accessed around August 2016

Budd T, Sharp C, Mayhew P (2005) "Offending in England and Wales: first results from the 2003 Crime and Justice Survey." Home Office Research Study No. 275. London: Home Office Research, Development and Statistics Directorate.

Clarke R, Lancaster T (2006) Eliminating the successor to plagiarism? Identifying the usage of contract cheating sites. Paper presented at the proceedings of 2nd international plagiarism conference

Clarke R, Lancaster T (2013) Commercial aspects of contract cheating. Paper presented at the proceedings of the 18th ACM conference on innovation and technology in computer science education

Cohen LE, Felson M (1979) Social change and crime rate trends: a routine activity approach. Am Sociol Rev 44:588-605

Cornish DB, Clarke RV (1986) The reasoning criminal: rational choice perspectives on offending. Springer-Verlag, NY

Cornish DB, Clarke RV (2008) "The rational choice perspective." In Environmental criminology and crime analysis, edited by R. Wortley and Lorraine Mazerolle, 21-47. Cullompton, UK: Willan Publishing

Curman ASN, Andresen MA, Bratingham PJ (2015) Crime and place: a longitudinal examination of street segment patterns in Vancouver, BC. J Quant Criminol 31:127-147. doi:10.1007/s10940-014-9228-3

Curtis GJ, Clare J (2017) How prevalent is contract cheating and to what extent are students repeat offenders? J Acad Ethics 15(2):115-124. doi:10.1007/s10805-017-9278-x

Curtis GJ, Vardanega L (2016) "Is plagiarism changing over time? A 10-year time-lag study with three points of measurement." Higher Education Research and Development. doi: 10.1080/07294360.2016.1161602

Eck JE (2003) Police problems: the complexity of problem theory, research and evaluation. Crime Prevention Studies 15:79-113

Eck JE, Eck EB (2012) Crime place and pollution: expanding crime reduction options through a regulatory approach. Criminol Public Policy 11(2):281-316. doi:10.1111/j.1745-9133.2012.00809.x

Farrell G, Phillips C, Pease K (1995) Like taking candy: why does repeat victimization occur? Br J Criminol 35(3):384-399

Felson M, Clarke RV (1998) Home Office research, development and statistics directorate. In: Opportunity makes the thief: practical theory for crime prevention - police research series, paper 98

Hodgkinson T, Curtis H, MacAlister D, Farrell G (2015) "Student academic dishonesty: the potential for situational prevention." Journal of Criminal Justice Education. doi:10.1080/10511253.2015.1064982

Jackson G (2016) Individual assessment mark analysis and the difficulties of acting retrospectively. In: WA forum on contract cheating. Curtin University, Western Australia

Lancaster T, Clarke R (2012) Dealing with contract cheating: a question of attribution. Paper presented at the proceedings of 1st annual Higher Education Academy conference in science, technology, engineering and mathematics

Lines L (2016) "Ghostwriters guaranteeing grades? The quality of online ghostwriting services available to tertiary students in Australia." Teaching in Higher Education, 21(8):889-914

Maxwell A, Curtis GJ, Vardanega L (2006) Plagiarism among local and Asian students in Australia. Guid Conselling 21:210-215

McCabe DL, Trevino LK (1993) "Academic dishonesty: honor codes and other contextual influences." J High Educ $64(5): 522-538$

Ogilvie J, Stewart A (2010) The integration of rational choice and self-efficacy theories: a situational analysis of student misconduct. Aust N Z J Criminol 43(1):130-155

Pease K, Ignatans D (2016) The global crime drop and changes in the distribution of victimisation. Crime Science 5(11):1-6. doi:10.1186/s40163-016-0059-4

Rigby D, Burton M, Balcombe K, Bateman I, Mulatu A (2015) Contract cheating and the market in essays. J Econ Behav Organ 111:23-37

Sampson R, Eck JE (2008) "Super controllers: Can I be your Superman?" 19th Annual POP Conference. http://www. popcenter.org/conference/conferencepapers/2008/supercontrollers.pdf

Sampson R, Eck JE, Dunham J (2010) Super controllers and crime prevention: a routine activity explanation of crime prevention success and failure. Secur J 23(1):37-51 
Scott MS, Goldstein H (2005) "Shifting and sharing responsibility for public safety problems. Problem-Oriented Guides for Police, Response Guides Series No. 3." In. US Department of Justice Office of Community Oriented Policing Services (COPS)

Sivasubramaniam S, Kostelidou K, Ramachandran S (2016) A close encounter with ghost-writers: an initial exploration study on background, strategies and attitudes of independent essay providers. Int J Educ Integr 12(1):1-14. doi:10.1007/s40979-016-0007-9

Skogan WG (1981) Issues in the measurement of victimization, vol 200. US Department of Justice, Bureau of Justice Statistices, Washington, DC

Tillyer MS, Eck JE (2011) Getting a handle on crime: a further extension of routine activities theory. Secur J 24(2):179-193

Townsley M, Homel R, Chaseling J (2003) Infectious burglaries: a test of the near repeat hypothesis. Br J Criminol 43(3):615-633

Walker M, Townley C (2012) Contract cheating: a new challenge for academic honesty. J Acad Ethics 10(1):27-44

Wallace MJ, Newton PM (2014) Turnaround time and market capacity in contract cheating. Educ Stud 40(2):233-236. doi:10.1080/03055698.2014.889597

Zafarghandi AM, Khoshroo F, Barkat B (2012) An investigation of Iranian EFL masters students' perceptions of plagiarism. Int J Educ Integr 8:69-85

Submit your manuscript to a SpringerOpen ${ }^{\circ}$ journal and benefit from:

- Convenient online submission

- Rigorous peer review

- Open access: articles freely available online

- High visibility within the field

- Retaining the copyright to your article

Submit your next manuscript at $\gg$ springeropen.com 